\title{
Changes in selected metabolic parameters in patients over 65 receiving hydrochlorothiazide plus amiloride, atenolol or placebo in the MRC elderly trial
}

Damian J. Damian ${ }^{1,2^{*}}$, Roseanne McNamee ${ }^{2}$ and Matthew Carr $^{2}$

\begin{abstract}
Background: Treatment of hypertension reduces incidence of stroke, myocardial infarction and heart failure perhaps partly by controlling different metabolic parameters. There is limited information regarding the changes in potassium, sodium, weight, cholesterol and glucose levels in patients using anti-hypertensives. This study aimed to determine changes in potassium, sodium, glucose, cholesterol, weight, urea and urate levels in patients using anti-hypertensives. Furthermore, to describe these changes and differences between the atenolol, hydrochlorothiazide plus amiloride and placebo arms of the Medical Research Council (MRC) elderly randomised controlled trial.
\end{abstract}

Methods: Patients were randomly allocated to one of the three treatment arms. Measurements were taken at baseline, end of year one and end of year two in 4396 subjects. Linear Mixed Models (LMM) were used to determine the longitudinal profiles of sodium, potassium, weight, cholesterol, glucose, urea and urate. Estimates of changes within groups and difference between groups were obtained.

Results: Patients randomised to receive hydrochlorothiazide + amiloride experienced a significantly greater mean reduction in potassium, sodium and weight compared to placebo at end of year one - mean differences in change -0 . $18 \mathrm{mmol} / \mathrm{L},(95 \% \mathrm{Cl}:-0.21,-0.15) ;-1.45 \mathrm{mmol} / \mathrm{L},(95 \% \mathrm{Cl}:-1.62,-1.29)$ and $-0.46 \mathrm{kgs}(95 \% \mathrm{Cl}:-0.73,-0$. 20) respectively, and greater increases in cholesterol, urea and urate - mean differences in change $0.16 \mathrm{mmol} / \mathrm{L}$, (95 \% Cl: 0.10,0.22); $0.77 \mathrm{mmol} / \mathrm{L}$, (95 \% Cl: 0.68, 0.87) and $53.10 \mu \mathrm{mol} / \mathrm{L},(95 \% \mathrm{Cl}: 49.35,56.85)$ respectively. Changes were in the same direction but smaller in the atenololarm except for potassium and weight (increases). No group differences in glucose were found.

Conclusion: Results were in line with expectation except for lack of change in glucose in the hydrochlorothiazide + amiloride arms.

Keywords: Anti-hypertensive, Hydrochlorothiazide, Amiloride, Atenolol, Metabolic parameters, MRC

\section{Background}

Hypertension is present in at least $25 \%$ of adults under the age of 50 , and $50 \%$ of those who are older [1]. It is responsible for $13 \%$ of global deaths, $55 \%$ of cerebrovascular disease, $45 \%$ of heart disease and $61 \%$ of cardiovascular deaths, and further linked to incidences of

\footnotetext{
* Correspondence: d_jeremy5@yahoo.com

${ }^{1}$ Community Health Department, Kilimanjaro Christian Medical Centre, P. O. Box 3010, Moshi, Tanzania

${ }^{2}$ Biostatistics, Institute for Population Health, University of Manchester, Manchester, UK
}

(c) 2016 The Author(s). Open Access This article is distributed under the terms of the Creative Commons Attribution 4.0 International License (http://creativecommons.org/licenses/by/4.0/), which permits unrestricted use, distribution, and reproduction in any medium, provided you give appropriate credit to the original author(s) and the source, provide a link to the Creative Commons license, and indicate if changes were made. The Creative Commons Public Domain Dedication waiver (http://creativecommons.org/publicdomain/zero/1.0/) applies to the data made available in this article, unless otherwise stated. kidney disease, affecting high, low and middle-income countries [2]. Those living with uncontrolled hypertension grew from 605 million to 978 million worldwide between 1980 and 2008, making it highly relevant to contemporary medical practice [3].

Treatments for hypertension - which aim to reach and maintain acceptable blood pressure levels $(<140 /$ $90 \mathrm{mmHg}$ ) - include angiotensin converting enzyme inhibitors (ACEs), angiotensin receptor blockers (ARBs), calcium channel blockers (CCBs), diuretics and betablockers. In the UK, recommended first line treatments 
have changed over time; CCBs are currently favoured as first line treatment for those aged over 55 years and for some ethnic groups at all ages, but thiazide or thiazidelike diuretics may also be recommended as first- or second-line therapy in certain cases $[1,4]$. In the US, the recommendations for first line treatments in the 2014 $8^{\text {th }}$ Joint National Committee on Prevention, Detection, Evaluation, and Treatment of High Blood Pressure (JNC) report continue to include thiazide type diuretics as well as ACEs, ARBs and CCBs [5]. Diuretics were found to be the most commonly prescribed drug in 2009-2010 in the US National Health and Nutrition Examination Survey population with the most common type being thiazide type diuretics $[6,7]$. A thiazide diuretic, hydrochlorothiazide + amiloride, was used in the UK MRC trial which we report on in this paper; this drug remains in common use at the time of writing [8].

Thiazide diuretics lower blood pressure by blocking reabsorption of sodium ions in the distal renal convoluted tubule and therefore draw water to be excreted as urine. This lowers blood volume leading to a reduction in cardiac output, and a reduction in peripheral resistance $[1,9]$. Increased excretion of sodium, and perhaps some weight loss, are expected [10, 11]. However, their use is also associated with increased excretion of potassium- in extreme cases causing hypokalaemia - due to an increased exchange rate in potassium for sodium [12-16]. To counteract this, the use of a potassium sparing diuretic - on their own only weakly diuretic - may be used in combination.

Thiazide diuretics are known to increase serum urate concentrations, potentially increasing the occurrence of gout and gouty attacks and may also lead to low concentrations of urea [8, 17-19]. Moreover, the use of thiazide diuretics - and beta-blockers - is known to affect glucose homeostasis through potential $\beta$-pancreatic cell damage; they are associated with undesirable metabolic changes including decreased insulin secretion and sensitivity and decreased glucose tolerance $[20,21]$. By causing increased excretion of potassium, thiazides can worsen glucose intolerance as low potassium inhibits insulin secretion [22], although there is limited evidence to support this [23]. However, this leads to an aggravated metabolic profile and an increased risk of new-onset diabetes mellitus [21, 24].

The 1980s UK MRC hypertensive trial among patients aged over 65 compared three treatment regimens: hydrochlorothiazide combined with potassium sparing amiloride, the beta blocker atenolol and placebo [24]. Hydrochlorothiazide + amiloride were shown to be more effective than atenolol for prevention of stroke and MI, as also found elsewhere [20, 24-26]. A report on blood pressure reduction in the treatment arms was also published [27] and recently updated [26]. But, although data on sodium, potassium, cholesterol, glucose, urate, urea and weight were collected for two years, there has been no report on how these parameters were affected. The continued use of hydrochlorothiazide makes these data highly relevant to current practice as does the data from the atenolol group. Beta-blockers block the action of catecholamines on portions of the sympathetic nervous system (those being the beta-adrenergic or $\beta 1$ and $\beta 2$ receptors) [28], in order to reduce heart rate, cardiac contractive force, and cardiac output [29]. Although they are no longer recommended by NICE as a first-line treatment option $[1,30]$, beta-blockers are known to have equal or greater effectiveness in the young compared with other anti-hypertensives [20, 25].

The objective of this work was to see how weight, potassium, sodium, cholesterol, glucose, urea and urate levels changed over time and whether the changes were different in the three arms. As noted, the results of the study in terms of blood pressure changes, mortality and cardio/cerebrovascular morbidity have already been published [24, 26, 27].

\section{Methods}

\section{Data source and type}

The data come from a Medical Research Council (UK) sponsored trial of anti-hypertensive medications in older adults which concluded in 1990 [24]. This was a randomized, placebo controlled, single blind trial (RCT) with two active arms (atenololand hydrochlorothiazide + amiloride) and a placebo arm. There were 4396 patients enrolled in total and they were followed for up to five years post-enrolment. Patients in diuretic arm received hydrochlorothiazide $50 \mathrm{mg}$ plus amiloride $5 \mathrm{mg}$ daily. However, due to metabolic disturbances observed after one year, all patients were transferred to a lower dose (hydrochlorothiazide $25 \mathrm{mg}$ plus amiloride $2.5 \mathrm{mg}$ ). In the beta-blocker arm, patients received atenolol $50 \mathrm{mg}$ once daily. If patients did not achieve target blood pressure after 12 weeks in this arm, the dose was increased (atenolol $100 \mathrm{mg}$ ); the calcium channel blocker nifedipine (doses up to $20 \mathrm{mg}$ daily) and other supplementary drugs could be used if further control was needed [24]. The patients were seen by the research doctors and nurses at regular intervals in order to monitor their blood pressure and other parameters including weight, potassium, sodium, cholesterol, glucose, urea and urate levels. The latter set were measured at recruitment and end of years one and two of follow-up; unfortunately, there is no information available on the measurement protocol for these parameters.

\section{Missing data}

Although the measurement schedule was fixed, not all patients have all the planned measurements owing to 
drop-out from the trial and because some patients may have died. The analyses here have been done on available data only but we conducted preliminary analyses to see whether those who later had missing data were different at baseline from those who did not.

\section{Statistical analysis}

Changes over the first two years of the trial in potassium, sodium, glucose, weight and cholesterol were determined and compared between the randomised treatment arms regardless of adherence to treatment, i.e. according to the principle of Intention-To-Treat (ITT) analysis. The main analyses were based on fitting a Linear Mixed Models (LMM) to the data with time treated as a categorical variable and with an unstructured covariance structure; to study differences over time between groups, the model included group"time 'interaction' terms. Estimates of mean change within groups - and their Standard Errors (SE) and differences between groups (hydrochlorothiazide + amiloride versus placebo, atenolol versus placebo and hydrochlorothiazide + amiloride versus atenolol) were extracted from these models. The advantage of this analysis approach over use of, say, paired and unpaired t-tests is that data from all patients can be used including from patients who had an incomplete data schedule. The variance components of the LMM models were set up to allow for the fact that within-group patient variability of most parameters tended to increase over time. The main focus of the analysis is the comparison of changes in the active treatment groups compared to each other and the placebo group.

\section{Results}

\section{Background characteristics of patients}

The 4396 patients enrolled in the trial were randomised to receive hydrochlorothiazide + amiloride (24.6\%), atenolol (25.1\%) or placebo (50.3\%). The median patient age (years) recorded during recruitment was 70 (ranging from 65 to 75$)$ and $58.2 \%(2,560)$ were female. At baseline, the mean glucose level amongst patients was $3.35 \mathrm{mmol} / \mathrm{L}$; the average weight $70.16 \mathrm{kgs}$; the mean potassium level $4.22 \mathrm{mmol} / \mathrm{L}$; the mean sodium level $141.59 \mathrm{mmol} / \mathrm{L}$; the mean cholesterol level $6.47 \mathrm{mmol} / \mathrm{L}$, the mean urea $5.91 \mathrm{mmol} / \mathrm{L}$ and mean urate level $338.56 \mu \mathrm{mol} / \mathrm{L}$. The baseline characteristics are compared between randomisation groups in Table 1; there are no important differences.

\section{Completed measurements per patient}

Table 2 shows the number of measurements recorded per person at the three visits for various parameters. The majority of participants 3936 (89.5\%) had all 3 measurements taken for weight. Nearly three quarters of patients had all measurements recorded for sodium, potassium and urate. Almost two thirds of patients had all measurements for cholesterol, urea and glucose. The percentage of patients who died over the two years in the hydrochlorothiazide + amiloride arm was $12.4 \%$, in the atenolol arm $15.2 \%$, and in the placebo arm $14.2 \%$, which explains some of the missing data. Sixty-two patients $(1.4 \%)$ had died by end of year one.

\section{Changes in outcome variables over time}

Additional file 1: Table S1 shows the mean and SD of the measures for all treatment groups combined at each time point based on the available data for each visit; the numbers of patients vary between time points. These data show little change (less than $0.1 \mathrm{SD}$ ) in mean weight, glucose, cholesterol, or potassium over the first two years of the trial. The mean sodium decreased in the first year while urea and urate levels increased.

Table 1 Baseline characteristics of the study population $(n=4396)$

\begin{tabular}{|c|c|c|c|}
\hline \multirow[t]{2}{*}{ Characteristics } & \multicolumn{3}{|l|}{ Treatment group } \\
\hline & Hydrochlorothiazide + amiloride & Atenolol & Placebo \\
\hline Number of patients enrolled & $1081(24.6)$ & $1102(25.1)$ & $2213(50.3)$ \\
\hline Male, $n(\%)$ & $454(42.0)$ & $456(41.4)$ & $926(41.8)$ \\
\hline Age, years & $70.4 \pm 2.7$ & $70.3 \pm 2.8$ & $70.3 \pm 2.7$ \\
\hline Weight, kg & $70.1 \pm 12.4$ & $70.4 \pm 12.5$ & $70.0 \pm 12.6$ \\
\hline Serum potassium, mmol/Lł & $4.2 \pm 0.4(n=1046)$ & $4.2 \pm 0.4(n=1072)$ & $4.2 \pm 0.4(n=2160)$ \\
\hline Serum sodium, mmol/Lł & $141.6 \pm 2.0(n=1055)$ & $141.6 \pm 2.0(n=1083)$ & $141.6 \pm 2.0(n=2173)$ \\
\hline Glucose, mmol/Lł & $3.4 \pm 0.7(n=999)$ & $3.4 \pm 0.7(n=1025)$ & $3.4 \pm 0.7(n=2051)$ \\
\hline Serum cholesterol, mmol/Lł & $6.5 \pm 1.3(n=1054)$ & $6.5 \pm 1.2(n=1075)$ & $6.4 \pm 1.2(n=2154)$ \\
\hline Serum urea, $\mathrm{mmol} / \mathrm{L} \neq$ & $6.0 \pm 1.4(n=1036)$ & $5.9 \pm 1.4(n=1066)$ & $5.9 \pm 1.3(n=2128)$ \\
\hline Serum urate, $\mu \mathrm{mol} / \mathrm{L} \neq$ & $341.8 \pm 70.5(n=1002)$ & $336.8 \pm 71.4(n=1030)$ & $337.8 \pm 70.5(n=2053)$ \\
\hline
\end{tabular}

¥Sample sizes for those with data on each measure are also shown 
Table 2 Number of measurements recorded per patient for each parameter (total patients $=4396$ )

\begin{tabular}{lllll}
\hline Parameter & \multicolumn{4}{l}{ Number of measurements recorded } \\
\cline { 2 - 5 } & $5(\%)$ & & 3 \\
\hline None & 1 & 2 & $35(10.4)$ & $3936(89.5)$ \\
Serum potassium, $\mathrm{mmol} / \mathrm{L}$ & $21(0.5)$ & $494(11.2)$ & $636(14.5)$ & $3245(73.8)$ \\
Serum sodium, $\mathrm{mmol} / \mathrm{L}$ & $15(0.3)$ & $489(11.1)$ & $598(13.6)$ & $3294(74.9)$ \\
Glucose, mmol/L & $45(0.3)$ & $561(12.8)$ & $913(20.8)$ & $2877(65.5)$ \\
Serum cholesterol, mmol/L & $22(0.5)$ & $490(11.2)$ & $652(14.8)$ & $3232(65.7)$ \\
Serum urea, $\mathrm{mmol} / \mathrm{L}$ & $45(1.0)$ & $560(12.7)$ & $904(20.6)$ & $2887(65.7)$ \\
Serum urate, $\mu \mathrm{mol} / \mathrm{L}$ & $18(0.4)$ & $512(11.6)$ & $737(16.7)$ & $3129(71.2)$ \\
\hline
\end{tabular}

Except for weight, the SDs of the parameters tended to increase over time.

\section{Comparisons between estimates of change over time between treatment groups}

All available data for each parameter were included in the LMM statistical models. The models was used to estimate within-patient changes over time and to test whether these changes differed significantly between groups; these results are presented in Table 3. In considering results for each outcome, it is important to allow for any changes over time which might have occurred regardless of active treatment; hence changes in the placebo group are also shown.

\section{Potassium}

In the placebo arm, the change in the mean potassium level in year one compared to year zero was close to zero but there was a marginally significant increase in year 2 compared to year 1 of $0.02 \mathrm{mmol} / \mathrm{L}$. At the end of year 1, patients in hydrochlorothiazide + amiloride arm had a statistically significant mean change in potassium level of $-0.18 \mathrm{mmol} / \mathrm{L}$ compared to year zero, which was also significantly different from the (near zero) change in the placebo arm: (95\% CI for mean difference in changes: $-0.21,-0.15)$. Furthermore, there was a significant change of $0.04 \mathrm{mmol} / \mathrm{L}$ in year two compared to year one in the hydrochlorothiazide + amiloride group, but this was not statistically significant compared to the placebo group change in the same period: (mean difference in changes $0.02 \mathrm{mmol} / \mathrm{L}, 95 \%$ CI: $-0.01,0.07)$. In the atenolol arm, there was a statistically significant increase in the mean potassium level in year one compared to year zero of $0.07 \mathrm{mmol} / \mathrm{L}$ and a non-significant change of $-0.03 \mathrm{mmol} / \mathrm{L}$ in year two compared to year one. The differences between atenolol arm and placebo arm in the changes in potassium in year $1 v s$. year 0 and in year $2 v s$. year 1 were statistically significant: mean difference in changes of $0.07 \mathrm{mmol} / \mathrm{L}, 95 \% \mathrm{CI}:(0.04,0.11)$ and $-0.5 \mathrm{mmol} / \mathrm{L}$, $95 \%$ CI: $-0.08,-0.01)$ respectively. The differences between the hydrochlorothiazide + amiloride arm change (D) and atenolol arm change (B) were statistically significant: in year $1 v s$. year 0 , the mean difference (D-B) was $-0.25 \mathrm{mmol} / \mathrm{L}, 95 \% \mathrm{CI}$ : $(-0.29,-0.22)$, while for year 2 vs. year 1 changes, the mean difference (D-B) was $0.07 \mathrm{mmol} / \mathrm{L}, 95$ \% CI: $(0.03,0.11)$.

\section{Sodium}

In the placebo group, the change in the mean sodium level in year one compared to year zero was $-0.19 \mathrm{mmol} / \mathrm{L}$ and in year 2 compared to year 1 was close to zero. The

Table 3 Mean (SE of mean) within-patient changes over time by treatment group

\begin{tabular}{|c|c|c|c|c|c|c|c|}
\hline \multirow[t]{2}{*}{ Changes } & Potassium & Sodium & Glucose & Cholesterol & Weight & Urea & Urate \\
\hline & Mean changes (SE) & Mean changes (SE) & Mean changes (SE) & Mean changes (SE) & Mean changes (SE) & Mean changes (SE) & Mean changes (SE) \\
\hline \multicolumn{8}{|l|}{ Placebo } \\
\hline $\begin{array}{l}\text { Yr1 vs. } \\
\text { YrO }\end{array}$ & $-0.00(0.01)$ & $-0.19(0.05)^{* *}$ & $-0.00(0.02)$ & $-0.03(0.02)$ & $-0.45(0.08)^{* *}$ & $0.08(0.03)^{* *}$ & $3.35(1.09)^{* *}$ \\
\hline $\begin{array}{l}\text { Yr2 vs. } \\
\text { Yr1 }\end{array}$ & $0.02(0.1)^{* *}$ & $-0.00(0.05)$ & $0.05(0.02)^{* *}$ & $0.07(0.02)^{* *}$ & $-0.23(0.07)^{* *}$ & $0.16(0.03)^{* *}$ & $3.89(1.17)^{* *}$ \\
\hline \multicolumn{8}{|c|}{ Hydrochlorothiazide + amiloride } \\
\hline $\begin{array}{l}\text { Yr1 vs. } \\
\text { YrO }\end{array}$ & $-0.18(0.01)^{* * * *}$ & $-1.64(0.07)^{* * * *}$ & $0.03(0.03)$ & $0.13(0.02)^{* * *}$ & $-0.91(0.11)^{* * *}$ & $0.85(0.04)^{* * *}$ & $56.45(1.57)^{* * *}$ \\
\hline $\begin{array}{l}\text { Yr2 vs. } \\
\text { Yr1 }\end{array}$ & $0.04(0.04)^{* *}$ & $0.14(0.08)$ & $0.04(0.03)$ & $-0.01(0.03)^{*}$ & $-0.26(0.11)^{* *}$ & $0.13(0.05)^{* *}$ & $-3.21(1.67)^{*}$ \\
\hline \multicolumn{8}{|l|}{ Atenolol } \\
\hline $\begin{array}{l}\text { Yr1 vs. } \\
\text { YrO }\end{array}$ & $0.07(0.01)^{* * *}$ & $-0.78(0.07)^{* * *}$ & $-0.01(0.03)$ & $0.04(0.02)^{*}$ & $0.05(0.11)^{*}$ & $0.62(0.04)^{* * *}$ & $43.00(1.55)^{* * *}$ \\
\hline $\begin{array}{l}\text { Yr2 vs. } \\
\text { Yr1 }\end{array}$ & $-0.03(0.01)^{*}$ & $-0.14(0.08)$ & $0.03(0.03)$ & $0.08(0.03)^{* *}$ & $-0.03(0.11)$ & $0.21(0.05)^{* *}$ & $4.81(1.68)^{* *}$ \\
\hline
\end{tabular}

*Indicates $P<0.05$ and refers to test for difference in change in active treatment group compared to placebo group

**Indicates $P<0.05$ and refers to within-patient changes over time in each group 
former change was statistically significant (95 \% CI: $-0.09,-0.29)$. Compared to year zero, at the end of year 1, patients in hydrochlorothiazide + amiloride arm had a statistically significant mean change in sodium level of $-1.64 \mathrm{mmol} / \mathrm{L}$. This fall in the hydrochlorothiazide + amiloride group was significantly greater than in the placebo group (mean difference in changes $-1.45 \mathrm{mmol} / \mathrm{L}, 95 \% \mathrm{CI}:-1.62,-1.29)$. There was a change of $0.14 \mathrm{mmol} / \mathrm{L}$ in year two compared to year one in the hydrochlorothiazide + amiloride group; this change was not statistically significant and not significantly greater compared to the placebo group (mean difference in changes $0.14 \mathrm{mmol} / \mathrm{L}, 95 \% \mathrm{CI}$ : $-0.04,0.33)$. In the atenolol arm, there was a statistically significant change in the mean sodium level in year one compared to year zero of $-0.78 \mathrm{mmol} / \mathrm{L}$ and a non-significant change of -0.14 units in year two compared to year one. The difference in changes in sodium in atenolol group compared to placebo group was statistically significant (mean difference in changes $-0.59 \mathrm{mmol} / \mathrm{L}, 95 \% \mathrm{CI}:-0.76,-0.42)$ for year $1 v s$. year 0 but not significant for year $2 v s$. year 1 (mean difference in changes $-0.13 \mathrm{mmol} / \mathrm{L}, 95 \%$ CI: $-0.32,-0.06)$. Also, the difference between the hydrochlorothiazide + amiloride arm and atenolol arm changes were statistically significant but in different directions in the two periods: in year $1 v s$. year 0 , the mean difference (D-B) was $-0.87 \mathrm{mmol} / \mathrm{L}, 95 \% \mathrm{CI}$ : $(-1.07,-0.67)$ while in year $2 v s$. year 1 , it was $0.27 \mathrm{mmol} / \mathrm{L}, 95 \% \mathrm{CI}:(0.05,0.50)$.

\section{Glucose}

The change in the mean glucose level in year one compared to year zero in the placebo arm was close to zero and $0.05 \mathrm{mmol} / \mathrm{L}$ in year 2 compared to year 1 . The latter change was statistically significant (95\% CI: 0.01, 0.09). Patients in the hydrochlorothiazide + amiloride arm had a non-significant mean change in glucose level of $0.03 \mathrm{mmol} / \mathrm{L}$ in year one compared to year zero and $0.04 \mathrm{mmol} / \mathrm{L}$ in year two compared to year one. The differences in the changes in glucose in year $1 v s$. year 0 and year 2 vs. year 1 between hydrochlorothiazide + amiloride arm and placebo arm were not statistically significant (. mean difference in changes $0.03 \mathrm{mmol} / \mathrm{L}, 95 \% \mathrm{CI}$ : $-0.04,0.09)$ and $-0.01 \mathrm{mmol} / \mathrm{L}, 95 \% \mathrm{CI}:-0.08,0.06)$ respectively. In the atenolol arm, there was a non-significant change in the mean glucose level in year one compared to year zero of $-0.01 \mathrm{mmol} / \mathrm{L}$ and $0.03 \mathrm{mmol} / \mathrm{L}$ in year two compared to year one. The differences in the changes in glucose in year 1 vs. year 0 and year $2 v s$. year 1 between atenolol arm and placebo arm were not statistically significant i.e. mean difference in changes of $-0.01 \mathrm{mmol} / \mathrm{L}, 95 \% \mathrm{CI}:-0.07,0.05)$ and $(-0.02 \mathrm{mmol} / \mathrm{L}),(95 \% \mathrm{CI})(-0.08,0.05)$ respectively.
Likewise the difference between the hydrochlorothiazide + amiloride arm and atenolol arm changes (D-B) were not statistically significant: $0.04 \mathrm{mmol} / \mathrm{L}, 95 \% \mathrm{CI}:(-0.04,0.11)$ in year 1 vs. year 0 , and $0.01 \mathrm{mmol} / \mathrm{L}, 95 \% \mathrm{CI}:(-0.07$, 0.09 ) in year $2 v s$. year 1.

\section{Cholesterol}

In the placebo arm, the mean change in cholesterol level in year one compared to year zero was $-0.03 \mathrm{mmol} / \mathrm{L}$ and in year 2 compared to year 1 was $0.07 \mathrm{mmol} / \mathrm{L}$. The latter change was statistically significant (95\% CI: 0.03 , 0.11 ). Compared to year zero, at the end of year 1, patients in hydrochlorothiazide + amiloride arm had a statistically significant mean change in cholesterol level of $0.13 \mathrm{mmol} / \mathrm{L}$. This change was significantly different compared to the placebo group change (mean difference in changes $0.16 \mathrm{mmol} / \mathrm{L}, 95 \% \mathrm{CI}: 0.10,0.22$ ). There was a non-significant change of $-0.01 \mathrm{mmol} / \mathrm{L}$ in year two compared to year one in the hydrochlorothiazide + amiloride group, but this was significantly different from the placebo group whose cholesterol has increased in this period (mean difference in changes $-0.08 \mathrm{mmol} / \mathrm{L}$, $95 \%$ CI: $-0.15,-0.02)$. In the atenolol arm, there was a non-significant change in the mean cholesterol level in year one compared to year zero of $0.04 \mathrm{mmol} / \mathrm{L}$ and a statistically significant change of $0.08 \mathrm{mmol} / \mathrm{L}$ in year two compared to year one. The difference in changes in cholesterol levels between the atenolol group and the placebo group was statistically significant in year $1 v s$. year 0 (mean difference in changes $0.07 \mathrm{mmol} / \mathrm{L}, 95 \%$ CI: $0.02,0.13)$ but not significant in year $2 \mathrm{vs}$. year 1 (mean difference in changes $0.01 \mathrm{mmol} / \mathrm{L}, 95 \% \mathrm{CI}$ : $-0.05,0.07)$. Also, the difference between the hydrochlorothiazide + amiloride arm and atenolol arm changes were statistically significant but in different directions: in year 1 vs. year 0 , the mean difference (D-B) was $0.08 \mathrm{mmol} / \mathrm{L}, 95 \% \mathrm{CI}$ : $(0.02,0.15)$ while in year $2 \mathrm{vs}$. year 1 , it was $-0.09 \mathrm{mmol} / \mathrm{L}, 95 \% \mathrm{CI}:(-0.17,-0.02)$.

\section{Weight}

In the placebo arm, there were statistically significant change in mean weight in year one compared to year zero $-0.45 \mathrm{kgs} 95 \% \mathrm{CI}(-0.29,-0.60)$ and in year 2 compared to year 1: $-0.23 \mathrm{kgs} 95 \% \mathrm{CI}$ : $(-0.38,-0.09)$. Patients in hydrochlorothiazide + amiloride arm had a statistically significant mean change in weight of -0.91 kgs in year one compared to year zero and $-0.26 \mathrm{kgs}$ in year two compared to year one. The differences between hydrochlorothiazide + amiloride arm and placebo arm in the changes in weight in year $1 v s$. year 0 was statistically significant (mean difference in changes of $-0.46 \mathrm{kgs}$, 95 \% CI: $-0.73,-0.20$ ) but not in year 2 vs. year 1 , (mean difference in changes of $-0.03 \mathrm{kgs}, 95 \% \mathrm{CI}$ : $-0.29,0.23)$. In the atenolol arm, there were non-significant changes 
in mean weight in year one compared to year zero of $0.05 \mathrm{kgs}$ and of $-0.03 \mathrm{kgs}$ in year two compared to year one. The differences in the changes in weight between atenolol arm and placebo arm in year $1 v$ s. year 0 was statistically significant (mean difference in changes of $0.50 \mathrm{kgs}$, (95 \% CI: 0.23, 0.76) but not significant between year $2 v s$. year 1 (mean difference in changes of $0.20 \mathrm{kgs}, 95 \%$ CI: $-0.06,0.46)$. The difference between the hydrochlorothiazide + amiloride arm and atenolol arm changes in weight was statistically significant in the first period - mean difference (D-B) of $-0.96 \mathrm{kgs}, 95 \%$ CI: $(-1.27,0.65)$ but not in the second - mean difference (D-B) of $-0.23 \mathrm{kgs}, 95 \%$ CI: $(-0.57,0.10)$.

\section{Urea}

In the placebo arm, there were statistically significant mean changes in urea in year one compared to year zero - $0.08 \mathrm{mmol} / \mathrm{L}$ (95 \% CI: 0.03, 0.14) - and in year 2 compared to year $1-0.16 \mathrm{mmol} / \mathrm{L}$ (95\% CI: 0.10, 0.22). Patients in the hydrochlorothiazide + amiloride arm had a statistically significant mean change in urea of $0.85 \mathrm{mmol} / \mathrm{L}$ (95 \% CI: $0.78,0.93)$ in year one compared to year zero and of $0.13 \mathrm{mmol} / \mathrm{L}$ (95\% CI: $0.03,0.22$ ) in year two compared to year one respectively. The differences in the changes in urea between hydrochlorothiazide + amiloride arm and placebo arm in year $1 v s$. year 0 was statistically significant (mean difference in changes of $0.77 \mathrm{mmol} / \mathrm{L},(95 \%$ CI: $0.68,0.87)$ but not statistically significant in year $2 \mathrm{vs}$. year 1 (mean difference in changes of $-0.03 \mathrm{mmol} / \mathrm{L}, 95 \% \mathrm{CI}:-0.15,0.08)$. In the atenolol arm, there were statistically significant changes in the mean urea in year one compared to year zero of $0.62 \mathrm{mmol} / \mathrm{L}$ (95 \% CI: $0.54,0.70$ ) and $0.21 \mathrm{mmol} / \mathrm{L}$ (95 \% CI: 0.11, 0.302) in year two compared to year one. The differences in the changes in urea between atenolol arm and placebo arm in year $1 v s$. year 0 was statistically significant (mean difference in changes of $0.54 \mathrm{mmol} / \mathrm{L}$, $95 \%$ CI: $0.44,0.63)$ but non-significant between year 2 vs. year 1 (. mean difference in changes of $0.05 \mathrm{mmol} / \mathrm{L}$, $95 \%$ CI: $-0.07,0.16)$. The difference between the hydrochlorothiazide + amiloride arm and atenolol arm changes was statistically significant for year $1 v$ s. year 0 - mean difference (D-B) was $0.24 \mathrm{mmol} / \mathrm{L}, 95 \% \mathrm{CI}:(0.13,0.35$ but not in year 2 vs. year 1 - mean difference (D-B) was $-0.08 \mathrm{mmol} / \mathrm{L}, 95$ \% CI: $(-0.22,0.05)$.

\section{Urate}

In the placebo group, the changes in urate in year one compared to year zero was $3.35 \mu \mathrm{mol} / \mathrm{L}$ (95 \% CI: 1.21, 5.49) and in year 2 compared to year 1 was $3.89 \mu \mathrm{mol} / \mathrm{L}$ (95 \% CI: 1.59, 6.19). Patients in the hydrochlorothiazide + amiloride arm had a statistically significant mean change in urate of $56.45 \mu \mathrm{mol} / \mathrm{L}$ (95 \% CI: 53.37, 59.52) in year one compared to year zero and a non-significant change of $-3.21 \mu \mathrm{mol} / \mathrm{L}$ (95 \% CI: -6.48, 0.06) in year two compared to year one. The differences in the changes in urate between hydrochlorothiazide + amiloride arm and placebo arm in year $1 v s$. year 0 and year 2 $v s$. year 1 were statistically significant (mean difference in changes of $53.10 \mu \mathrm{mol} / \mathrm{L}, 95 \% \mathrm{CI}: 49.35,56.85$ and of $-7.10 \mu \mathrm{mol} / \mathrm{L}, 95 \% \mathrm{CI}:-11.09,-3.10$ respectively). In the atenolol arm, there was a statistically significant change in the mean urate in year one compared to year zero of $43.00 \mu \mathrm{mol} / \mathrm{l}(95 \%$ CI: 39.96, 46.04) and $4.81 \mu \mathrm{mol} / \mathrm{L}$ (95 \% CI: 1.53, 8.10) in year two compared to year one. The difference in the changes in urate between atenolol arm and placebo arm in year $1 \mathrm{vs}$. year 0 was statistically significant (mean difference in changes $39.65 \mu \mathrm{mol} / \mathrm{L}, 95 \% \mathrm{CI}: 35.93,43.37)$ but not significant between year $2 v s$. year 1 (mean difference in changes of $0.93 \mu \mathrm{mol} / \mathrm{L}, 95 \% \mathrm{CI}:-3.08,4.93)$. The difference between the hydrochlorothiazide + amiloride arm and atenolol arm changes was statistically significant in both periods but not in the same direction: in year 1 vs. year 0 , the mean difference (D-B) was $13.43 \mu \mathrm{mol} / \mathrm{L}, 95 \% \mathrm{CI}$ : $(9.10,17.76)$, while in year 2 vs. year 1 , the mean difference (D-B) was $-8.02 \mu \mathrm{mol} / \mathrm{L}, 95 \% \mathrm{CI}:(-12.75,-3.30)$.

\section{Discussion}

The conduct of this trial has been described elsewhere: no serious problems in terms of validity have been reported $[24,26,27]$. As already noted, hydrochlorothiazide + amiloride were shown to be more effective than atenolol for prevention of stroke and MI [24]. Although the hydrochlorothiazide + amiloride arm showed the greatest drop-off in BP in the initial stage of the trial, both active treatment groups reached similar average levels after 2 years of follow-up [26]. Therefore, it was of interest to see whether there was evidence that other metabolic parameters - which could play a part in patient morbidity and mortality - were affected by these treatments.

Given complete data arising from a randomised controlled trial, ITT comparisons between randomised groups allow us to estimate the causal effect of the 'intention to treat' with a drug. However true efficacy can be underestimated by ITT comparisons when there is non-adherence or treatment cross-over as the trial progresses. The ability to produce unbiased evidence may also be compromised when there is missing data. However, this issue is less problematic in the first year of the trial: data was $83-90 \%$ complete for all parameters except glucose $(77 \%)$ at end of year one.

In the first year of the trial, patients in diuretic arm received hydrochlorothiazide $25 \mathrm{mg}$ or $50 \mathrm{mg}$ plus amiloride $2.5 \mathrm{mg}$ or $5 \mathrm{mg}$ daily [24]. Due to metabolic disturbances observed among patients who were using highest dose, all patients transferred to a lower dose (hydrochlorothiazide $25 \mathrm{mg}$ plus amiloride $2.5 \mathrm{mg}$ ). 
Some of the observed differences between year 1 and year 2 changes among patients randomised in diuretic arm might be explained by changes in dosage. Also we would expect treatment supplementation may have been more pronounced in the second year compared to the first, thus blurring the contrasts between treatment effects. These considerations suggest more emphasis is placed on the year one results, which we now discuss in terms of changes relative to placebo arm changes.

In the first year, hydrochlorothiazide + amiloride treatments appeared to reduce sodium, weight and potassium compared to placebo. The reduction in sodium that might be attributed to the treatment, i.e. the difference between hydrochlorothiazide + amiloride and placebo arm changes, was substantial - on average, equivalent to 0.72 of baseline SD (bSD). The beta-blocker, atenolol, also reduced sodium compared to placebo but to a lesser extent $(0.29$ bSD), and had little effect on weight i.e. weight gain (0.04 bSD). This combination of findings supports the previous research which showed diuretic treatments being associated with weight losses rather than the beta blockers which are known to be associated with weight gains $[10,11,31,32]$. The decrease in potassium attributable to the hydrochlorothiazide + amiloride treatments was non-trivial - equivalent to $0.46 \mathrm{bSD}$, while mean potassium levels were increased by $0.19 \mathrm{bSD}$ in the atenolol group. The changes in serum potassium in hydrochlorothiazide + amiloride group were in line with findings from previous studies [33, 34]. Potassiumsparing diuretics, despite not fully - are known to correct the fall in serum potassium by increasing serum potassium concentrations [35]. The impacts of beta blocker on potassium match those observed in earlier studies and are not of clinical importance $[13,36]$.

From the present data, it appeared that neither regimen affect glucose levels in the first year; this is surprising given a report elsewhere of withdrawal rates of 6.9, 5.8 and 2.7 per 1000 person-years -which we estimate as $4.0 \%, 3.4 \%$ and $1.5 \%$ of patients - in hydrochlorothiazide + amiloride, atenolol and placebo arms respectively for "impaired glucose tolerance" [24]. In our data, no patient in the hydrochlorothiazide + amiloride arm and only one in the atenolol arm had a glucose level higher than $7 \mathrm{umol} / \mathrm{L}$ compared to eight in the placebo arm. This incompatibility with results from the original report suggests that our data may be incomplete and therefore our results should be downplayed.

Cholesterol levels increased significantly over year one in the hydrochlorothiazide + amiloride arm; measured against the change in the placebo group, the increase attributable to treatment was of the order of $0.13 \mathrm{bSD}$; the atenolol arm also showed a significant increase compared to placebo which again was rather small (0.06 bSD). These findings differ from those obtained by Lakshaman et al. which showed none of the drugs had a long-term adverse effects on plasma lipids and lipoprotein profiles in men with hypertension [37]. The increase in cholesterol levels in hydrochlorothiazide + amiloride arm is in accord with previous studies which indicated relative increase in cholesterol level which varied with dose and/or race $[38,39]$.

Both active treatments arms showed large increases in mean urea and mean urate levels over year one, but the increases for the hydrochlorothiazide + amiloride group were significantly greater than in the atenolol group. For urea, the increases were equivalent to $0.56 \mathrm{bSD}$ and 0.39 bSD respectively, while for urate they were $0.75 \mathrm{bSD}$ and $0.56 \mathrm{bSD}$. Other studies have shown consistent finding that diuretic and beta blocker treatments gives similar changes in kidney function [36, 39]. Increases in urate levels associated with treatment with diuretics (but not potassium-sparing diuretics) and beta blockers have been reported previously $[8,18,36,40]$ and so results here are not unexpected. Bengtsson has recommended monitoring of serum uric acid levels after treatments with diuretics [40]. However, in recent times, there has been new debate [41-43], as to its significance for both hypertension and cardiovascular disease: "an innocent bystander" or a "central player"? Commenting on work by Viazzi et al., which found that increased serum uric acid (sUA) levels at baseline blunted the antihypertensive impact 1.5 years later of lifestyle changes in children, Bavish concluded that sUA is emerging "as a key factor modulating hypertension". Elsewhere [44], in an observational study based on the UK CPR Database, hypertensive patients over 65 years with stable BP medication who were also prescribed allopurinol showed a small reduction in SBP and DBP over time compared to comparable patients who were not, again suggesting a causal role for sUA, although baseline sUA did not predict in this study. In view of this and other evidence, the increase in sUA in the hydrochlorothiazide + amiloride and atenolol arms in this study are notable: perhaps BP reduction might have been greater has there not been concomitant increases in urate.

The key strengths of this study are its large sample size, relative long follow-up and the use of sophisticated statistical methods in analysis (LMM). This method of statistical analysis uses all data from all patients including those with an incomplete data schedule. Furthermore, the analysis involved estimation of changes within and between treatment groups over time. Although parameters may not have changed sufficiently to warrant withdrawal from the study for most patients, for scientific reasons, it is important to understand the degree of average change in the group, including when there is little change. Indeed, results from large, well-powered 
studies, which show little change, are important for demonstrating safety.

Despite being a multicentre study whereby measurements were not performed in the same core laboratory - the results of this study are not likely to be affected by inter laboratory differences. The results which compare the same patients at different time points (within-patient comparisons) and comparisons between treatment groups are not likely to be affected by inter laboratory differences in technique as we presume each clinic used one laboratory and the same laboratory was used for a given patient. Furthermore, randomisation to treatment groups was in stratified blocks within each sex and clinic.

Our 'intention to treat' analysis followed the approach of the original mortality study by comparing outcomes by intended treatment, despite the treatment changes within the treatment period. Such analyses are acknowledged to address important pragmatic questions [45].

It might be argued that patient aged 65-75 are healthier today than 30 years ago but the evidence suggests that deterioration is merely postponed: "indices of heath that used to prevail at age 70 now prevail at age 80 " [46]. We believe that these results remain relevant to patients who present with systolic pressures of $160 \mathrm{mmHg}$ or more and who are prescribed similar drugs. As noted in the Introduction, the US 2014 recommendations for first line treatments continue to include thiazide type diuretics as well as beta blockers [5].

\section{Conclusion}

This study has shown that hydrochlorothiazide + amiloride and atenolol treatments increase cholesterol, urea and urate levels in a short period of time. Both active treatments arms showed a significant decrease in sodium levels over the first year of the trial. , No differences were found in glucose levels among patients randomised in hydrochlorothiazide + amiloride and atenolol arms when compared to placebo arm.

\section{Additional file}

Additional file 1: Table S1. Mean (SD) of outcome variables over time (all groups combined). (DOCX $12 \mathrm{~kb}$ )

\section{Abbreviations \\ ACEs: Angiotensin converting enzyme inhibitors; ARBs: Angiotensin recepto blockers; bSD: Baseline standard deviation; CCBs: Calcium channel blockers; Cl: Confidence Interval; ITT: Intention-To-Treat; LMM: Linear mixed model: MI: Myocardial Infarction; MRC: Medical Research Council; SD: Standard deviation; SE: Standard error; UK: United Kingdom; US: United States}

\section{Acknowledgements}

Although this work was not funded by them, we wish to acknowledge the support of the UK Medical Research Council (Award No: R102506) for a parallel project which inspired the present one.
Funding

None.

Availability of data and materials

Due to data agreements with the NHS Information Centre (reference number MR28/MR28a), the supporting data is not openly available.

\section{Authors' contributions}

DJD and RM designed the study. DJD, RM and MC analysed the data and drafted the manuscript. DJD and RM interpreted the results. DJD and RM contributed to the final draft of the manuscript. All authors gave their final approval to the manuscript.

\section{Authors' information}

DJD (BSC, MSC) - is a PhD fellow in the School of Public Health and Family Medicine at the University of Cape Town, South Africa; a graduate at the University of Manchester, UK and a Biostatistician at Kilimanjaro Christian Medical Centre, Tanzania.

RM (BSC, MSc, PhD, FFOM) - is a Professor of Epidemiological Statistics in the Centre for Biostatistics in the Institute of Population Health at the University of Manchester, United Kingdom.

MC (BSC, MSc, PhD) - is a Biostatistician in the Centre for Mental Health and Risk at the University of Manchester, United Kingdom.

\section{Competing interests}

The authors declare that they have no competing interests.

\section{Consent for publication}

Not applicable.

\section{Ethics approval and consent to participate}

Data agreement to allow further access to data was obtained in 2008 from the NHS Information Centre (reference number MR28/MR28a). Further work was funded by UK Medical Research Council (Award No: R102506) and the specified work included examination of the longitudinal parameters.

Although the analyses in this paper were not directly funded, the objectives overlap with those of the funded work for which data access was granted.

Received: 4 May 2016 Accepted: 28 September 2016

Published online: 04 October 2016

\section{References}

1. National Institute for Health and Care Excellence. Hypertension - Clinical management of primary hypertension in adults. NICE clinical guideline. 2011. p. 127.

2. World Health Organization. Global health risks: Mortality and burden of disease attributable to selected major risks. Bull World Health Organ. 2009; 87:646-6.

3. Danaei G, Finucane MM, Lin JK, Singh GM, Paciorek CJ, Cowan MJ, Farzadfar F, Stevens GA, Lim SS, Riley LM, Ezzati M. Global Burden of Metabolic Risk Factors of Chronic Diseases Collaborating Group (Blood Pressure). National, regional, and global trends in systolic blood pressure since 1980: systematic analysis of health examination surveys and epidemiological studies with 786 country-years and 5.4 million participants. Lancet. 2011;377:568-77.

4. Opie L, Schal R. Evidence-based evaluation of calcium channel blockers for hypertension equality of mortality and cardiovascular risk relative to conventional therapy. J Am Coll Cardiol. 2002;39:315-22.

5. James PA, Oparil S, Carter BL, Cushman WC, Dennison-Himmelfarb C, Handler J, Lackland DT, LeFevre ML, MacKenzie TD, Ogedegbe O, Smith SC, Svetkey LP, Taler SJ, Townsend RR, Wright JT, Navra AS, Ortiz E. 2014 evidence-based guideline for the management of high blood pressure in adults: report from the panel members appointed to the Eighth Joint National Committee (JNC 8). JAMA. 2014;311:507-20.

6. Redburn KA, Niebylski ML. Excellence and notable achievement awards from the world hypertension league: a call for 2015 nominations. J Clin Hypertens. 2014;16:927-9.

7. Gu Q, Burt VL, Dillon CF, Yoon S. Trends in antihypertensive medication use and blood pressure control among united states adults with hypertension: the national health and nutrition examination survey, 2001 to 2010. Circulation. 2012;126:2105-14. 
8. Wilson L, Nair KV, Saseen JJ. Comparison of new-onset gout in adults prescribed chlorthalidone vs. hydrochlorothiazide for hypertension. J Clin Hypertens (Greenwich). 2014;16:864-8.

9. Department of Veterans Administration. Veteran adminstration/department of defence practise guidelines for diagnosis and management of hypertension in the primary care setting. Washington D.C: Veteran Adminstration and Department of Defence; 2004.

10. Davis BR, Davis BR, Oberman A, Blaufox MD, Wassertheil-Smoller S, Hawkins CM, Cutler JA, Zimbaldi N, Langford HG. Effect of antihypertensive therapy on weight loss. The trial of antihypertensive interventions and management research group. Hypertension. 1992;19:393-9.

11. Freis ED, Reda DJ, Materson BJ. Volume (weight) loss and blood pressure response following thiazide diuretics. Hypertension. 1988;12:244-50.

12. Pollare $T$, Lithell $H$, Berne C. A comparison of the effects of hydrochlorothiazide and captopril on glucose and lipid metabolism in patients with hypertension. N Engl J Med. 1989;321:868-73.

13. Sica SA. Antihypertensive therapy and its effects on potassium homeostasis. J Clin Hypertens. 2006;8:67-73.

14. Doi Y, Aoi W, Suzuki S, Seto S, Baba K, Yano K. Changes in total body potassium during long-term thiazide treatment: Effects of potassium supplements on total body and serum potassium in hypertensive patients with thiazide treatment. Int J Angiol. 1994;3:142-7.

15. Chrysant SG, Neller GK, Dillard B, Frohlich ED. Effects of diuretics on lipid metabolism in patients with essential hypertension. Angiology. 1976;27:707-11.

16. Andreucci VE, Del Canton A (eds.). Diuretics: Basic, Pharmacological, and Clinical Aspects: Proceedings of the International Meeting on Diuretics, Sorrento, Italy, May 26-30, 1986. Naples: Springer Science \& Business Media; 2012.

17. Hwang KS, Kim G-H. Thiazide-induced hyponatremia. Electrolyte Blood Press. 2010;8:51-7.

18. Bruderer S, Bodmer M, Jick SS, Meier CR. Use of diuretics and risk of incident gout: a population-based case-control study. Arthritis Rheumatol (Hoboken, NJ). 2014;66:185-96.

19. Wofford MR, Andrew ME, Brown A, King D, Pickett RA, Stevens J, Wyatt S, Jones DW. Obesity hypertension in the atherosclerosis risk in communities cohort: implications of obesity guidelines. J Clin Hypertens (Greenwich). 1999:1:27-32.

20. Aksnes TA, Kjeldsen SE, Mancia G. The effect of antihypertensive agents on new-onset diabetes mellitus: time to amend the guidelines? Am J Cardiovasc Drugs. 2006;6:139-47.

21. Lindholm L, Persson M, Alaupovic P, Carlberg B, Svensson A, Samuelsson O. Metabolic outcome during 1 year in newly detected hypertensives: results of the Antihypertensive Treatment and Lipid Profile in a North of Sweden Efficacy Evaluation (ALPINE study). J Hypertens. 2003;21:1563-74.

22. Ramsay LE, Yeo WW, Jackson PR. Diabetes, impaired glucose tolerance and insulin resistance with diuretics. Eur Heart J. 1992;13(Suppl G):68-71.

23. Lindholm LH, Carlberg B, Samuelsson O. Beta blockers in primary hypertension: Do age and type of beta-blocker matter? J Hypertens. 2006;24:2143-5.

24. MRC Working Party. Medical Research Council trial of treatment of hypertension in older adults: principal results. MRC Working Party. BMJ. 1992;304:405-12.

25. Khan N, McAlister FA. Re-examining the efficacy of beta-blockers for the treatment of hypertension: a meta-analysis. CMAJ. 2006;174:1737-42.

26. Carr MJ, Bao Y, Pan J, Cruickshank K, McNamee R. The predictive ability of blood pressure in elderly trial patients. J Hypertens. 2012;30:1725-33.

27. Lever AF, Brennan PJ. MRC trial of treatment in elderly hypertensives. Clin Exp Hypertens. 1993;15:941-52.

28. Mancia G, Sega R, Milesi C, Cessna G, Zanchetti A. Blood-pressure control in the hypertensive population. Lancet. 1997;349:454-7.

29. Street Edith. 17th expert committee on the selection and use of essential medicines. Geneva: World Health Organization; 2009.

30. Narkiewicz K, Kjeldsen SE, Oparil S, Hedner T. Beta-blockers as sub-optimal treatment for hypertension: time for first-line therapy revision? Blood Press. 2006;15:323-4.

31. Meiner S. Gerontologic Nursing. Maryland Heights: Elsevier Mosby. 2014

32. Sharma AM, Pischon T, Hardt S, Kunz I, Luft FC. Hypothesis: -adrenergic receptor blockers and weight gain : a systematic analysis. Hypertension. 2001;37:250-4

33. Poulsen L, Friberg M, Noer I, Krusell L, Pedersen OL. Comparison of indapamide and hydrochlorothiazide plus amiloride as a third drug in the treatment of arterial hypertension. Cardiovasc Drugs Ther. 1989;3: $141-4$.
34. Leppla D, Browne R, Hill K, Pak CYC. Effect of amiloride with or without hydrochlorothiazide on urinary calcium and saturation of calcium salts. Clin Endocrinol Metab. 1983;57:920-4.

35. Morgan DB, Davidson C. Hypokalaemia and diuretics: an analysis of publications. Br Med J. 1980;280:905-8.

36. Messerli FH (ed.). Kidney in Essential Hypertension: Proceedings of the Course on the Kidney in Essential Hypertension held at New Orleans, Louisiana, March 18-19, 1983. Springer Science \& Business Media. 2012.

37. Lakshman MR, Reda DJ, Materson BJ, Cushman WC, Freis ED. Diuretics and beta-blockers do not have adverse effects at 1 year on plasma lipid and lipoprotein profiles in men with hypertension. Department of Veterans Affairs Cooperative Study Group on Antihypertensive Agents. Arch Intern Med. 1999;159:551-8.

38. Kasiske BL, Ma JZ, Kalil RS, Louis TA. Effects of antihypertensive therapy on serum lipids. Ann Intern Med. 1995;122:133-41.

39. Savage PJ. Influence of Long-term, Low-Dose, Diuretic-Based, Antihypertensive Therapy on Glucose, Lipid, Uric Acid, and Potassium Levels in Older Men and Women With Isolated Systolic HypertensionThe Systolic Hypertension in the Elderly Program. Arch Intern Med. 1998;158:741.

40. Bengtsson C. Elevated serum uric acid levels during treatment with antihypertensive drugs. Acta Med Scand Suppl. 1979;628:69-71.

41. Kanbay M, et al. Uric acid in metabolic syndrome: From an innocent bystander to a central player. Eur J Intern Med. 2016;29:3-8.

42. Bavishi C, Messerli FH, Rimoldi SF. Serum uric acid in primary hypertension. Hypertension. 2016;67:845-7.

43. Viazzi F, et al. Increased serum uric acid levels blunt the antihypertensive efficacy of lifestyle modifications in children at cardiovascular risk. Hypertens (Dallas, Tex 1979). 2016;67:934-40.

44. Beattie CJ, et al. Allopurinol initiation and change in blood pressure in older adults with hypertension. Hypertens (Dallas, Tex 1979). 2016;64:1102-7.

45. Hollis $S$, Campbell F. What is meant by intention to treat analysis? Survey of published randomised controlled trials. BMJ. 1999;319:670-4.

46. Vaupel JW. Biodemography of human ageing. Nature. 2010;464:536-42.

\section{Submit your next manuscript to BioMed Central and we will help you at every step:}

- We accept pre-submission inquiries

- Our selector tool helps you to find the most relevant journal

- We provide round the clock customer support

- Convenient online submission

- Thorough peer review

- Inclusion in PubMed and all major indexing services

- Maximum visibility for your research

Submit your manuscript at www.biomedcentral.com/submit
) Biomed Central 